\title{
The Effect of the Volume and Type of Capital on the Formation of Lifestyle Based on Bourdieu'sthoughts
}

\author{
Zahra Taheri $^{1}$, Dr.Ali Hashemianfar ${ }^{2}$,Dr.Ali Rabbani ${ }^{3}$ \\ ${ }^{I}$ PhD candidate of Sociology, University of Isfahan, Isfahan, Iran \\ 2 Assistant Professor, Department of social sciences, University of Isfahan, Isfahan, Iran \\ 3Associate Professor, Department of social sciences, University of Isfahan, Isfahan, Iran
}

\begin{abstract}
With in-depth studies in the sociology of Bourdieu, and changes created by the events in the sixties in France,great help has been given to him to address the theoriesandconjugated theoretical and abstract thoughtsand experience. The result of such a link leads to the formation and restoration of the term of lifestyle so many years before language of thesociologieslike Simmel, Veblen, etc. have been expressed. This paper tries to explain the idea of Bourdieu's thoughts in definitions and classification of different types of capital and its role in shaping lifestyle of the people. In Bourdieu's view, the existence and size of different capitals moved to create different lifestyles, lifestyle-oriented product of capital system which is multi-faceted relationship with each other through understanding and into a hierarchical system that is developed and combines the durability of capital in a person's judgment and evaluation of a community.

Using documentary and analytical methods have been used to discussthesubject.
\end{abstract}

\section{Introduction}

Bourdieu is influential French sociologist after Durkheim (Tavasoli, 2004: 1). Mahar and his colleagues (1990) argue that Bourdieu's theoretical thinking is a combination of Marx, Durkheim, Weber, Saussure, Wittgenstein, and schools of thought of phenomenology, structuralism and analytical philosophy. In all combinations of Bourdieu, two things are important. Firstly, a theoretical position which he called the "generative structuralism". And the second point is his dissociationfrom classical Marxism.Theycomparedgenerative structuralism with Giddiness's structuration theory (Harker et al., 1990: 201 -205). This theoretical position is as the composition of the structural elements withanother approach that has the potential of causing the man to forget agency connected (Fowler, 1997: 2). His approach is attention to everyday life, but not to the ethno-methodologists and phenomenologists' method, but taking into consideration the material and social conditions arising individual perceptions and experiences. And meanwhile the "principle of ignorance" is a guide for his research. According to this principle, "... social phenomena should not only be found out in the awareness of people, but also in visual relations system in which they put (Wacquant, 2000: $332)$.

One of the strengths,methodologically, in the work of Pierre Bourdieu is that he believed that it should be a close and inseparable link between theory and empirical research. Bourdieurejected any novel theory that has no empirical stems and did not choose the pure experimentalism that was done in a theoretical gape. In his idea, experimentaland scientific research on the theory should go in accompany with falling in understanding social reality and avoid any theory of study or research to the understanding of the theory and causing damage both of them (Ritzier, 2002: 760). Integral of experimental research and theory in both his works namely differentiation (1984) and logic of action (1990) seems to peak (Wacquant, 2006: 253) Capital and its various forms, depending on which is distinct from Bourdieu and his theory of differentiation is primarily centered. Bourdieu received from capital is a thing beyond the meaning of money in the economy. In fact, source of general capital is the monetary and non-monetary assets which can be taken in tangible and intangible form (Anherier, 1995: 826).In Bourdieu's words: "If we seek to understand the social world, the idea of capital accumulation and its effect again refer to the social world" (Sharepour and Khoshfar, 2002: 134). "Capital" in Bourdieu theory is referred in any capacity, skills and abilities which are applied to the individual in society and can be attributed to acquire or earn in his relationship with the individuals and groups for the advancement of the position of winning. Obtaining the resourcesdependsoncapital and skills of actors in obtaining capital (Stevens,2000: 340). Agren believes that when the termof capital has been used in other fields, something lasting and enduring has been associated in mind. Term of capital, thereby is also something that involves maintaining its identity after repeated use, something that could work frequently to win, destroy, and acquire or improve (Agren, 1999: 6).

This study also explored the framework of Bourdieu's mind, definitions and categorizations of different capitals and the effect of varying amount of capital and explains them in shaping the lifestyle of people. 


\section{Definition And Withdrawingcapitals From The Bourdieu's Perspective}

According to Bourdieu (1985), any property, goods or resources that are valuable to society can be considered as a capital.And stratification on the basis of classis defined in terms of capital. Three factors might influence the capital of Bourdieu's view: 1-volume 2- composition and 3-trajectory. Volume is related to the capital. Composition is referred to relative frequency of economic, social and cultural aspects of the capital. In Bourdieu's theory, some people have small amounts of capital, both economically and culturally to the extent that the combination of the both them do not reach the target and put on lower hierarchy of the classes. But on the other hand, individuals may also be a combination of high levels of economic capital at their disposal, along with high levels of cultural capital in the upper class that put on upper class hierarchy. In contrast to the upper and lower class middle class, a variable combination of cultural and economic capital is at their disposal. Finally, the trajectory of Bourdieu's theory is important and is related to class mobility, whicheveryonemay earn a considerable cultural capital into economic and political situation and gain the considerable power and has mobility from the lower into upperclass(Momtaz, 2004: 153).

Bourdieu argues that the social structure of an advanced society is not analyzed just by stating a simple hierarchical analysis of the income and economic capital. But "the social structure of these communities is a very complicated social space in which a variety of social capitals in terms of social groups is distributed" (Wang, 2006: 316).

\section{TypesOf Capital}

Bourdieu (1986) in an articleentitled“the types of capitals"mentionedthree types of capital: economic, cultural, social and economic capital, also he used a fourth capitalas symbolic one. The notion of economic capital compared to other types that has a long history in social science literature, Bourdieu's work compared to other capitals in most of his works triesto develop and explain the concept of economic capital that has been less expressed. (Bourdieu, 1998: 57)

In Bourdieu theory, distribution of opportunities and values in society lie on the basis of having the four types of capital formation. In fact, the enjoyment level of economic, cultural, symbolic and physical capital status was specified in the social hierarchy (Javaheri, 2008: 65).

The remarkable thing about the types of capital in Bourdieu's work is that they are interchangeable.

Inhaler and colleagues (1995), based on index of different types of capital that are madebythe difference in the society, investigated the current unit of capital, and the hierarchy that had appeared (Table 1).

Table (1) comparison of the types of capital in Bourdieu theory

\begin{tabular}{|c|c|c|c|c|c|}
\hline $\begin{array}{c}\text { Capital } \\
\text { formation }\end{array}$ & Index & A basic distinction & Common unit & $\begin{array}{c}\text { The degree of } \\
\text { segmentation }\end{array}$ & $\begin{array}{c}\text { Hierarchy } \\
\text { grade levels }\end{array}$ \\
\hline Economic & $\begin{array}{c}\text { Economic } \\
\text { status }\end{array}$ & Material property & Money & Weak & Strong \\
\hline Social & $\begin{array}{c}\text { Social } \\
\text { Registeration }\end{array}$ & $\begin{array}{c}\text { Membership / non- } \\
\text { membership }\end{array}$ & $\begin{array}{c}\text { Social } \\
\text { communication }\end{array}$ & Strong & Weak \\
\hline Cultural & $\begin{array}{c}\text { Fame - } \\
\text { education }\end{array}$ & Known / not known & The Prestige & Strong & Strong \\
\hline Symbolic & $\begin{array}{c}\text { Hierarchy of } \\
\text { genres }\end{array}$ & Art / non-art & Legitimacy & Strong & Strong \\
\hline
\end{tabular}

Each of the capitals may be in two forms: embodiedand physical [i.e.it is in the mind] and identified [in the form of a real product], according to Bourdieu, people in order to get the best position compete together and ofcourse the exchanges of four types of capital cause it. In other words, theforms of capital are the determinants of social power and inequalities (Sharepour and Khoshfar, 1380: 31).

\section{The following is a brief mention of four types of capital 3-1- EconomicCapital}

The notion of economic capital is "properties and luxury goods that belong to an individual" (Bourdieu, 57: 1998) .In other words, possession of wealth and money, earning money, and other resources and the presentation of financial properties can be found on property ownership. Bourdieu's concept of economic capital and their origins lie in the economic zone (Saieimehr, 2004: 23).

Economic capital refers to the amount of material capital in the production system, which is close to the Marx's capital theory (Mumtaz, 2004: 150). Bourdieu from an angle was not interested in his study in economic field; he was more interested in the social and cultural capital. But on the other hand, the importance of economic capital of Bourdieu was the exchangeability of high capital compared to other ones, the rate which it gets very effective to raising the status of the individuals hierarchy (Attar, 2008: 161). 


\section{3-2-Social Capital}

For Bourdieu, social capital, physical or non-physical resources available to an individual or group has relatively durable network of communication and mutual respect are institutionalized or acquaintances (Field, 2006: 23).

From the perspective of Bourdieu (243: 1986), in his view, social capital consists of two components: 1. the membership of the group and social networks, 2. mutual recognition and authentication. Capital and power are almost synonymous. In fact, the process of concentration of different species of capital, capital of coercion instruments (police), economic capital, cultural capital and the state, in particular enablesto apply the various fields and special power converter (Fine, 2006: 104).

Bourdieu's capital is so that he knows money and power are synonymous. He distinct the social networks that a person rather than a forum can come out of this network chopped to social capital and social consequences is a distinction. The networks must not be equated with the production of social relationships; social networks because it would make it invisible. Social networks might be very dense, yet due to them unable to generate resources (Phillips, 2006).

Therefore, the acquisition of social capital is as a network that links everyone effectively to deploy and additionally depends on the amount of economic capital, cultural or symbolic occupation of the person who is related to them (Bourdieu, 2005: 147).

\section{3-3- Symbolic Capital}

It means having the dignity and prestige, the concept of symbolic capital, including the use of symbols used to legitimize their capital levels (Turner, 512: 1998). For Bourdieu, symbolic capital, including qualifications, competence, and credibilitygivesreputation and specific power to the holders (Bourdieu, 1998: 291).

Symbolic capital is a part of the cultural capital which can legitimize, define, and create the evaluationsandstyle. Symbolic capital is referred to prerequisite or at least the collection of all forms of capital. Symbolic capital to any forms (any economic capital, cultural, social, etc.) that a group of community finds and valuesit (Bourdieu, 2002: 154). In other word, key role of symbolic capital is to give legitimacy to other species exist and is only in the mind understandings, spread faster and understand thateconomic and cultural, social capital on the money, or test and document a link with the social networks, meanwhile in the other eye is symbolic capital (Attar, 2008: 163).

\section{3-4- Cultural Capital}

It means the possession and use of cultural goods and knowledge and cultural capital is a set of relationships, information, and data points that every person has used it to obtain a social position. In other word, cultural capital in the realm of possibility that a permanent renal cortex, group, tribe or class. Cultural capital can be divided into two categories: tangible (such as buildings, places, artwork, etc.) and intangible (in ideas, actions and values) (SalehiAmiri, 2007: 64).Bourdieu with Pasronat the first time in 1977 in his book "reproduction in education, society and culture" used the concept of cultural capital in their writing and by supporting this concept, social and cultural reproduction of French educational system are displayed. And differentiation in the cultural capital as an indicator of social status and power was introduced. Using this concept involved Bourdieu emphasized that the educational system of the ruling class, its advantagesare not be transmitted to their children (Wacquant, 2006:60).

Bourdieu argued that the cultural capital of post-warwesternsocieties, cultural capitals, qualifications and familiarity with the culture of the bourgeoisie were as an essential factor of opportunities in life accordingly and justify the unequal distribution of such capitals to individual talent and merit academic help to maintain and reproduce the social hierarchy (Wacquant, 2006:2).

\section{The Importance Of Cultural Capital Than Any Other Capitals In}

\section{The Formation Of Lifestyle}

Since among the types of capital, cultural capital plays an important role in Bourdieu's thought, he analyzed lifestyle and consumption that is based on the type of capital. This part of the article has been paid more attention to it.

Bourdieu determines the effect of cultural capital on performing expenditure, activity and lifestyle of the people is assured by appealing to a theory to explain the distinction stems. According to this theory, the holders of high cultural capital, with its high consumption of culture and art moved apart. But two other explanations are worth investigating, firstly a more cultural capital means having higher cognitive ability and talent in the field of cultural capital or the test. According to Brett,it could be said that test is initiative to work and the amount of capital determines the length of his step in that direction. Then each action which wants to become part of one's lifestyleshouldbefit to the special test of individual. 
Cultural capital, including ".... welltastes, style and good way, cognitive complexity, and the ability to accept and recognize the legitimate cultural products such as art, classical music, theater and literature ..." (Ven. E. Jesk, 1997:197) and is domination of any kind of symbolic systems (Dawson, 1985: 570). Cultural capital has various functions. Firstly, gaining legitimacy through the rest of the capitalsthatis subjected to become the cultural capital. A person who has esteem through cultural capital can impose his own narrative of the social to others. Secondly, the cultural capital means that a person can be separated from the requirements of daily life and a preferred choice in the field of culture. Bourdieu's own words,"pure aesthetics, ethics, or the mood over the selection of the requirements of the natural world and the social origins" (Bourdieu, 5: 1984).

\section{5-1- Dimensions Of Cultural Capital}

Pierre Bourdieu accounted cultural capital in a variety of knowledge, competence and cultural trends which has three main dimensions

A)EmbodiedorSubjective Cultural Capital (Imaginative):(in the form of lasting mental and physical qualities), such additional capital through sociability passed from parents to children. Or in other word, it is absorbed through the habituswhich is so much in the way of formal education and childhood (Attar, 2008: 162). Embodiedcultural capital is a wealth as an outer portion of a person (SharepourKhoshfar, 2002: 137). This capital is obtained by effort, experience and talent of the person and is eliminated by the owner of it and will not be transferredto someone else, such as memory, experimental and behavioral skills (Rouholamini, 1987: 34). Indeed, the cultural capital that is gradually internalizing has potential to strengths of his person have been established inside him(Noghani, 2002: 78). The capital can be a time of increased learning. The capital of the person involved and the type of behavior and therefore they can be immediatelytransferred (Niazi and Nosratabadi, 2007: 60).

Generally,this type of capital in Bourdieu's thought refers to lifestyle, methods and cultural preferences (Bourdieu, 1986: 246).

B) ObjectiveCultural Capital:(identification of cultural categories (images, Books and devices, etc.) (Attar, 2008: 162), this type of capital not only in the mind and body, but also in cultural and material objects, tools and mass media are found and socialgroups consume them or is possessed by individuals and families like journals, paintings, sculptures, images, books, dictionaries, tools, machineries, especially writing, etc., considerable point about this type of capital that can be owned only those who have imagined cultural capital and also obtain identified cultural capital. In other word,first type of cultural capital is the first requisite to seize second type (Bourdieu, 247: 1986). Thesecapitals are passed on to others. This exclusive property due to proximity and ease of access and ancillary facilitieshastraining and educational effects on the owners of capital (Rouhlamini, 1986: 34).

Due to its portability, this is a kind of capital in the form of a proposed economic and symbolic aspects of it can be preserved. However, it should not only be seen as an object material, such as a car or house. This type of capital is closely linked with internalizing cultural capital. Should bear it in mind is that what is the ability to transfer is legal ownership and is not necessarily the knowledge and insight necessary to understand and use (ownership of consumption utilities), which is an internal cultural capital. In short, all objects and cultural goods called objective cultural capital, but the nature of this capital is that have training effect on holders (Bourdieu, 1986: 246).

C) Embodiedcultural capital (in cultural institutions, based on tests, and scientific evidence (Attar, 2008: 162). The highest correlation occurs with the process of cultural capital in the education system; it is like having a degree from an accredited university and a valid driving license. This type of capital can be social or economic status of individuals and groups to raise (Johnson, 2005:300, and Movahedet al., 2010: 84).

The capital is not transferable and cannot be transmitted to people who are dependent on certain conditions (Rouholamini, 1365: 34). Since the material and symbolic tastes of qualifications, depends on the scarce (in terms of time, effort and money) may be enough to be useful to predict (Sharepour and Khoshfar, 2002: 137).

This section emphasizes strongly on education and family status. In more detailed expression, cultural capital in a way is effectively transferred within the family, in addition to the present amount of capital in the family is dependent on time of transferring of capital inside family. Meanwhile cultural capital is exclusively economic, mainly but not exclusively, is subjective. (Khademian, 2008: 39-38). The necessity of institutional cultural capital, first of all, is competent and talented individuals to obtain a variety of degrees and academic certificates. On the other hand, it requires the official institutions, the issue and the recognition of their qualifications. The distinguishing characteristic of this capital is to act as a bridge between economy and culture and the ability to involve the cultural capital, through the application of logical and formal way, in the form of economic capital. Embodied cultural capital is as a result of institutionalized rules and regulations for their own 
social status. The capital,with the help of social conditions such qualifications, career and employment verification, position stems. The capital, also gain transferable and cannot be transmitted to people who are dependent on certain conditions (Bourdieu, 1986: 246).

\section{5-2-Resources Of Cultural Capital}

A) Family:In all cultures, family is the main cause of children socialization. According to Giddiness, in modern societies, socialization mostly occurs in small family and extent. However, typically, one of the major factors of socialization, from childhood to adolescence then is a series of sequential development;human acts are related to each other (Giddiness, 1999: 75). Socialization is a process by which humans contact with other children, with disabilities, people have gradually become aware, knowledgeable and skilled in behavior methods, especially given the changing culture.

Family, a desire to perpetuate the existence of human society, with all attendants' privileges is dependent on root in the production strategy. Families in proportion to high cultural capital andthe relative weights of capital than larger economical capital allocate more investment in the education of their children. According to this model, today's families, especially elite families such as intellectuals, university professors and high levels of employment, in all advanced countriesgivegreat importance to the education of their children. This model helps to understand acknowledges that "the long and great educational centers that social graduates occupy the top positions, every day more and more are used by privileged members of society and children of top classes "(Bourdieu, 2001: 55).

According to Bourdieu, cultural orientation or habitsthat are unconsciously learned in the early stages of life are difficult to change and act very active in the subsequent formation of responses in the experiences of life. Children, class, cultural habits and the habits of their parents involve to determining the course of their life (Azadeh, 2004: 62).

B) Social classes:Main discussion of Bourdieuisuppersocial classes that allocate a certain cultural capital to themselves in its economic stratification hierarchy; in the way that people who are high social and economic hierarchy, have different levelofconsumption of cultural goods, delivery of methods, characters and models and in education field, the children of the upper classes find more cultural capital. Bourdieu argues that class and culture are located in vertical ranking and reinforce each other. High class culture, apparently, because of its superiority and, in fact due to dominance of the ruling class, culture has developed distinctive and recognizable. On the other hand, culture helps to class distinctions and financial and economic capitalsare used to describe a two-dimensional class model. Vertical dimension is indicator of volume of material capital and horizontal dimension is composition of capital and economic capital and its intensity. Cultural capital, mostly in academic environments and material capital is found in economic world (Samiei, 2000: 17). According to Bourdieu, the children who are belonged to the welfare class, often, at home, in the cultural activities and cultural goods and resources (books, resources and education and training)face further level of education and are more successful, compared with poor children who have less access to cultural capital (Noughani, 2004: 19).

\section{The Composition Of Capital Volume And Its Impact On The Formation Of A} Variety Of Lifestyle

Bourdieu's theory of forms of capital explainsthedifferences in consumption patterns in horizontal surfaces (unlike Veblen who explained consumption patternsin the vertical plane). Bourdieu is able to measure the volume of capital types among people in the class, but there is a difference between those consumption patterns and cultural influences job, itself, that is a source of cultural capital formation) explains the differences. Most important heritageofBourdieu's thought to sociologyof consumption and lifestyle is combining a variety of capital analysis to determine patterns of consumption and investigate the hypothesis of differentiating classes through cultural consumption and class basis of tests and cultural consumption.On the other hand, Bourdieu's emphasis on patterning actions taken as a result of the disposition requirementsis inspired from research methods and lifestyle patterns that the example of his work is used in the book of differentiation (Fazeli, 2003: 45-46).

Bourdieu's theory of classification and lifestyle includes exercise, sport and recreation because of association methods, etc. In fact,identification and embodimentarepreferences of individuals. As Bourdieu in terms of dialectical logic showstaking just a way to show the differences, but also it is a way to make distinctions. Different aesthetic preferences,tastesandstyles moved to create a different life. It affected his lifestyle and taste, and the consequence of character and disposition of the product's position in the social objective structures. The position of the individual in the social structure is determinant of his important tool of capital, as he showed the character and manners of generating two types of systems: one system of perception and evaluation of procedures, i.e.tastes and other systems that interact with the system of classification applied that cause categorization of both lifestyles. But this is the case because the lifestyle and consumption processes 
as its manifestation is a system of classification applied to the system of classification of actions (Shalchi, 2008: 101).

The dietary and lifestyle approach not to analyze the relationship between the political, economic, social and cultural structures which is not useful. In fact, that is what that Bourdieu has done. For Bourdieu until obvious manifestation of a person'slifestyle is equal to personality and self-concept (i.e.his abilities and values) this indicates a superficial face of esthetics and an everyday ethics. The meaning and function of each component and lifestyle in different classes, is various and this must be considered in any explanation (Bourdieu, 2002: 9-238). For this reason, he believes that if someone does understand this point, then he perceives conflict between reading poetry or philosophy, theater, music or reading bourgeois music, historical adventure narratives with a glossy journals, he will understand the conflict between walking, going camping and holiday in the mountains or countryside among professors and teachers with bourgeois luxury pleasures: "if anyone finds the worldsof these actions are to belong to different styles and cultural activities, social philosophies and recognition of world is much better understood than the actions."

Lifestyles vary according to Bourdieu's theoretical approach to reproduction of tastes between individuals and leads through the first distinctive character. Because lifestyle is the space in which the actors thereunder learn how to live, what they know best and what is beautiful. Therefore, Bourdieu, in the book called "distinction" tries to explain the relationship between aesthetics and social field that concerns taste and triesto criticize Kant's claims, based on a purely aesthetic and abstracted from social life according to the data collected from different social groups, since field studies show great differences of tastesandit is not justifiable with Kant's approach. The concept of differentiation, indicating the fact that the meaning of differentiation which are applied to a set of behaviors and styles extent to the population who lives different positionsin the view of capitalism thatappearsamong the various social fields (Bourdieu, 31: 1984).

\section{The Summary And Conclusions}

Summary of Bourdieu's view is that individuals and groups in society have different and differentiated situations (status or social space). Individual or group make within this state and its symbols, a system of social stratification in mind and hold (position). In this system, a set of preferences and choices (tastes) produced in the mind of the person or persons that meaning (value) through their relationships and conflictions conceived, the preferences and choices when in range of abilities and disabilities (the capital) and economic symbolic actions and assets reflected in the "lifestyle" and alter the expression of distinct social system reproduced. Bourdieu knowsthese differences in terms of class system and struggling to legal culture. When in range of preferences and choicesof abilities and disabilities (the capital) in the form of economic and symbolic actions and knowledge throughput will occur, "lifestyle" created distinct andin other words, the reproduction of the social system occurs. Bourdieu knows these extensions and differentiationsunderstandablein terms of class and culture legitimate dispute. In this way, the lifestyle, an opportunity to experience or proof of status in the social space, usually in the form of a weighty distances that he reserved his order is frequently confirmed.

Second, lifestyle is the result of social classification system. A system that continually transformed necessities into strategiesandinto acknowledges that individual preferences without imposed feel, it is considered as an options ahead is blocked. The same reason is meaning(values) of lifestyles. Therefore, the mean (value) inserts lifestyles of the system contains contradictions and relationships between components and obtaining a system including conflictions and relations between components and different social positions.

In clear expression, regarding met needs of individual he is given a chance to think less about the results and functions of his activities and properties and like an artist was thinking enjoying the order and selected fit of them. Bourdieu taking into consideration the lifestyle expresses a process that starts by away from necessities of life and climbing up the social hierarchy and highlights, Weber called this process "Stylization of life" during this process, the individual has the opportunity to have more throughput that will be used and the specific actions and their properties forgiven (Bourdieu, 2002: 9-201).

Bourdieu here acknowledges that such an opportunity to learn from both groups. First, they who have the greater economic capital and then the ones in second place who obtain cultural and symbolic capital.Society's history shows long war between the two groups of different communities that clear example of them is the bourgeois. With its economic capital they moved to the achievement of the second group that are true for artists prevent to be numeral face and away from its meaning in their service and outlets triggered of manifestation and authoritarian of culture and show their lifestyle in the form of culture and lifestyle as "legitimate".

Therefore, Bourdieu like Weber addresses social policy as a third social territory (in the realm of economics, culture, social) lifestyle and the culture and lifestyle legitimately ask, a large part of his analysis in the differentiation and other his works belong to the same category (Bourdieu, 2002: 238)

Bourdieu, in distinction explicitly acknowledges that social differences in a variety of social practices (economic and cultural) could be observed. He emphasized the need to the role along with economic andcultural 
capital to differentiate social (identities). He is in the process of modernization of certain forms of individuality which are produced in certain areas of social action-like taste, character-based lifestyle.

In his view, social and structural distinctions in recent years were expressed through forms of cultural expression of modernity increasingly being manufactured. All the actions taken to Bourdieu, the extraction and manipulation should be considered as a demonstration of mastery of a code of communication and should be considered as an "aesthetic attitude" and understood, as further demand of culture world (always implicitly) (Bourdieu, 8: 1984). He believes that the style and context of goods, especially those goods that are considered privileged andis to form one of the key signs of identity as well as the ideal weapon in distinguished strategies.

Bourdieu believes what is called lifestyle are known to lead to differentiate one from another, and has direct and provable relationship with capitals. What person in their life and what is alleged to be acquired is obtained.In Bourdieu's view, the existence and size of different capitals moved to create different lifestyles, lifestyle-oriented product of capital system which is multi-faceted relationship with each other through understanding and into a hierarchical system that is developed and combines the durability of capital in a person's judgment and evaluation of a community.

\section{References}

[1]. Azadeh, MansouredAzam, (2004), "Status inconsistency", PhD thesis of sociology, TarbiatModares University.

[2]. Stones, Rob, (2000), "Great thinkers of sociology", translated byMehrdadMirdamadi,Tehran:Markaz Press.

[3]. Bakak, Robert, (2002), "Consumption", translated byKhosroSabouri, Tehran: ShirazehPublication

[4]. Bourdieu, Pierre, (2005), "Capital forms", collected by KianTajbakhsh, "social capital: trust, democracy and development", translated by AfshinKhakbazan and Hassan Pouyan, Tehran: ShirazehPublication

[5]. Bourdieu, Pierre, (2002), "Sports actions and social actions", translated by MohammadrezaFarhadi, Arghavan Journal, No. 20.

[6]. Bourdieu, Pierre, (2001), "Action theory, practical reasons and rational choice”, translated byMortezaMardiha, Tehran:Noghsho-Negar

[7]. Tavasoli, Gholam Abbas, (2004), "An Analysis of Pierre Bourdieu's thought about the disputable social environment and role of Sociology", a social science, Serial No. 23, Vol. 11, No. 3, pp. 1-27.

[8]. Javaheri, Fatemeh, (2008), "The body and its social and cultural implications, cultural studies", 9thedition, the first issue, $37-$ 80 .

[9]. Chelbi, Masoud, (1996), “Sociology of order”, Tehran, Ney publication

[10]. Khademian, Talieh, (2008), "Lifestyle and cultural consumption: study in cultural sociology and cultural lifestyle of the Iranians", Tehran: Cultural and Artistic Institute, world of books Press.

[11]. Rouholamini, Mahmoud, (1986), "Culturalstudies", Tehran: Attar publications.

[12]. Ritzier, George, (2002), “Contemporary sociological theory”, translated by MohsenSalasi, Tehran: scientific publications.

[13]. SaeiMehr, Monireh, (2004), "Evaluation of social, cultural capitals and immigration and settlement in the big cities: case study Tabrizcity",M.A. thesis, University of Al-Zahra.

[14]. Samiei, Zohreh, (2000), "Effects of cultural and socioeconomic capitals families on children's educational and career success in Tehran", M.A. thesis, University of Al-Zahra.

[15]. Sharepour, Mahmoud andKhoshfar, Gholamreza, (2001), "Effect of cultural capital on youth social identity in Tehran (research project)", Tehran: Ministry of Culture and Islamic Guidance.

[16]. Sharepour, Mahmoud andKhoshfar, Gholamreza, (2002), "The relationship of sultual capital with social identity of the youth",Case Study of Tehran ", social science newsletter, No. 20, pp. 133-147.

[17]. Shalchi, Vahid, (2008), "Café shop, youth lifestyle", Journal of Cultural Studies, Vol. I, No. 1, Spring.

[18]. SalehiAmiri, Seyed Reza, (2007), "Cultural concepts and theories", Tehran: Phoenix Press, second edition.

[19]. Attar, Saeed, (2008), "Pierre Bourdieu, social space and social capital, political and economic data", $22^{\text {nd }}$ edition, No. 11 and 12, August and September.

[20]. Fazeli, Mohammad, (2008), "Picture of students' cultural life style", Journal of Cultural Research, Institute of Social and Cultural Studies, Ministry of Science, Research and Technology, Vol. I, No. 1, Spring.

[21]. Fazeli, Mohammad, (2003), "Consumer and lifestyle", Qom: SobhSadegh Press

[22]. Fine, Ben, (2006),"Social capital and theories ", translated by M. K.Savarian, Tehran: Center for Strategic Studies.

[23]. Fokouhi, N. (2006), "Pierre Bourdieu", electronic publication of the new season, $2^{\text {nd }}$ edition, No. 47.

[24]. Field, John. (2006), "Social Capital", translated by J. Mottaghi, Tehran: Institute of Social Security.

[25]. Phillips, James, (2006), "Myth of social capital in community development", translated by AmirNusratRouhani,Aftabpolitical, economic quarterly-magazine.

[26]. Giddiness, Anthony, (2008), "Modernity and identity, community and personal identity in the modern era", translated byNaserMovafaghian, Tehran: Ney publication.

[27]. Mumtaz, Farideh, (2004), "Introduction to the class of Bourdieu's perspective", research journal of Humanities: No. (32-41), pp160-149

[28]. Movahed, Majid et al. (1389), "Patterns and social life of young girls", Journal of Women's Studies, Volume 8, Number 1, Spring $79-105$.

[29]. Noughani, Mohsen (2005), "Cultural Capital and Higher Education", Journal of Culture and Art of Khorasan, $5^{\text {th }}$ edition, No. 13.

[30]. Noughani, Mohsen, (2004), "Education and cultural reproduction", social sciences development, new era, No. 3,2002

[31]. Niazi, Mohsen, staff of Nasrabadi, M., (2007), "Explaining the relationship between cultural capitalsoffamilies and the youth's social identity", National Culture Studies, Vol. VIII, No. 31.

[32]. Agren, P .O. (1999), "Virtual Community Life: A Disappearance to Third Capital"، Internet.

[33]. Anherier, H. K. Gerhard، J \&Romo، F .P.,(1995)، “ Forms of Capital and Social Structure in Cultural Fields: Examining Boudieus". No 4:859-90، American Journal of Sociology- Vo1. 100Social Topography

[34]. Bihagen2000:Bihagen. E. and Katz- Gerro .T. (2000),“Cultural consumption in Sweden: The Stabiltiy of Gender Differences”, Poetics 27.

[35]. Bourdieu, Pierre. (1998), "Practical Reason: On the Theory of Social Action”, Cambridge, UK: Polity Press. 
[36]. Bourdieu, Pierre. (1986), “The Forms of Capital in Handbook of Theory and Research for the Sociology of Education”.(ed.) JG. Richardson, New York: Greenwood Press, (pp. 241-258).

[37]. Bourdieu, Pierre. (1984), "Distinction: A Social Critique of the Judgment of Taste”, London, Routledge\&Keganpaul.

[38]. Bourdieu, Pierre. (1977), "Cultural Reproduction and Social Reproduction"، pp. 487-511 in J. Karaxel and A. H. Halsey (eds) Power and Ideology in Education` Oxford University Press‘ New York.

[39]. Burt, Ronalds. (2000), "A Primer on Crime and Delinquency Theory", Second Edition, Wards Worth

[40]. Dawson,Don,(1985), "On the analysis of class and leisure", Society and leisure, Vol.8, No.2, pp.563-572

[41]. Fowler, Bridget, (1997), "Pierre Bourdieu and Cultural Theory": Critical Investigations. SAGE Publications

[42]. Johnson, Louise. (2005), "Valuing the Arts: Theorizing and Realizing Cultural”, Australia: Deakin University Press.

[43]. Harker, Richard, Mahar, Cheleen, Wilkes, Chris,(1990) (eds.) "An Introduction to Work of Pierre Bourdieu", St., Martin's Presset Al.:201- 205

[44]. Mahar, Cheleen, Harker, Richard, Wilkes, Harker,(1990),"The Basic Theoretic position," pp.1-25, In Richard

[45]. McRobbie, Angela (2005), "The Uses of Cultural Studies", Sage Publication

[46]. Turner. J. H. (1998), "the Structure of Sociological Theory", Belmont, CA: Wadsworth Publishing Company

[47]. Yan, Lam Ka. (2006), "Underprivileged Students who succeed”, for the degree of Master of Philosophy at The University of Hong Kong

[48]. Van Eijck, Koen, (1997),"The impact of family background and educational attainment on cultural consumption: A sibling analysis". Poetics, Vol. 25, 1997, pp.195- 224

[49]. Wacquant, L., (2006), Pierre Bourdieu. Forthcoming in Rob Stones (ed.), KeyContemporaryThinkers(London and New York: Macmillan), new edition.

[50]. Wang, Shaoguang. (2006), The Uneven Distribution of Cultural Capital: Book Reading in Urban China. Modern China; 32; 315

[51]. Yan, Lam Ka., (2006),Underprivileged Students who succeed, for the degree of Master of Philosophy at The University of Hong Kong 